DOI: $10.20472 / E F C .2018 .010 .035$

\author{
KAROL SZOMOLÁNYI \\ University of Economics in Bratislava, Slovak Republic \\ MARTIN LUKÁČIK \\ University of Economics in Bratislava, Slovak Republic \\ ADRIANA LUKÁČIKOVÁ \\ University of Economics in Bratislava, Slovak Republic
}

\title{
ESTIMATE OF THE ELASTICITY OF SUBSTITUTION IN SLOVAK ECONOMY - A FREQUENCY FILTER SUR MODEL
}

\begin{abstract}
:
The elasticity of substitution between capital and labor in Slovak economy is estimated in the paper. To avoid normalization of the constant elasticity substitution production function problem, we focus in the capital and labor demand specification. Data series of capital, labor, output and their prices gathered from the National Bank of Slovakia macroeconomic database are used. To abstract from the business cycle shocks, data are modified by frequency filters. Finally, to avoid a false regression, the specifications are differenced. Since we do not reject the correlation between error terms of the specification, we use the seemingly unrelated regression method to estimate the coefficients. In result the estimated elasticity of substitution in the Slovak economy is relatively small; its value ranges from 0.03 to 0.11 .
\end{abstract}

\section{Keywords:}

elasticity of the input substitution, seemingly unrelated regression model, frequency filter

JEL Classification: C32, E23, E25 


\section{Introduction}

The recent studies (Chirinko, 2008; Klump, McAdam, Willman, 2012; La Grandville, 2009) highlight the importance of an elasticity of substitution between capital and labor. An important foundation is a positive impact of the elasticity of substitution on output. Empirical papers (Chirinko, Mallick 2017; Klump, McAdam, Willman, 2007) argue that the value of elasticity of substitution is less than one in many economies, which is inconsistent with the Cobb-Douglas form of production function. This fact should affect further research including production functions, such as research using Dynamic Stochastic General Equilibrium Models (DSGE) or research anchored in neoclassical growth theory. The aim of the paper is to estimate the elasticity of substitution in Slovak economy.

Many economists dealt with an estimating of the parameters of production function, see Chirinko (2008); Klump, McAdam, Willman (2012). Research on estimation of production functions uses supply side econometric specifications. They are a linearized form of production function and first order conditions of a representative firm maximizing profit. These conditions express both capital and labor demand.

Estimation of these econometric specifications is associated with both theoretical and statistical problems that make it difficult to choose a suitable approach to estimate the parameters of a production function. The main theoretical problem is the necessity to normalize the general form of the constant elasticity of substitution production function. It follows from the papers of La Grandville, (1989) and Klump, McAdam, Willman (2012) that the estimation of the linearized form of the production function can be associated with the specification error if the production function is not properly normalized. Normalization of the production function would not affect the estimation of the parameters only assuming the unit elasticity of the input substitution, i.e. in the case of the CobbDouglas production function.

Estimation of the basic normalization point is performed by averaging (Klump , McAdam, Willman 2007; Klump, McAdam, Willman, 2012). Given the transitive nature of the Slovak economy, we regard the approach of averaging as problematic. The conditions of the transitive economy would better correspond to the normalization around the steady state point proposed in the paper of Jones (2003), but such a point is difficult to estimate. As we will see in the theoretical part, production function normalization does not affect the value of the elasticity substitution in both capital and labor demand relationships.

From the statistical view, the problematic is the non-stationarity of the processes generating used corresponding time series the resulting false regression of the linear supply-side economical relationships. The usual solution to the non-stationarity of variables is the estimation of the corresponding cointegration relationship with the error correction model, as used in his work by Caballero (1994). In addition, the cointegration 
relationship is in line with the theory of rational behavior of a representative firm maximizing profit that is relevant in the long run. Chirinko, Mallick (2011) criticized this approach because the cointegration relationship between input/output ratio and inputprice/output-price ratio does not measure the elasticity of substitution. The criticism of these authors is presented in the theoretical part.

Chirinko, Mallick (2017) proposed to obtain long-term data using frequency filters. We will use this approach in our work. We focus on the estimation of labor and capital demand relationships in which the elasticity of substitution is measured as the negative value of the elasticity of the impact of input-price/output-price ratio on the input/output ratio. The common feature of our study with the study using the concept of normalization (Klump, McAdam, Willman, 2007) is an estimate of the supply-side economy system, but a linearized form of production function requiring proper normalization is not included in our system.

\section{Model}

Consider a normalized constant elasticity of substitution production function (CES) in the form:

$$
Q_{t}=Q_{0}\left[\pi_{0} A_{K t}\left(\frac{K_{t}}{K_{0}}\right)^{\frac{\sigma-1}{\sigma}}+\left(1-\pi_{0}\right) A_{L t}\left(\frac{L_{t}}{L_{0}}\right)^{\frac{\sigma-1}{\sigma}}\right]^{\frac{\sigma}{\sigma-1}}
$$

where output is denoted as $Q_{t}$, inputs capital and labor as $K_{t}$, and $L_{t}$. By lower index 0 are denoted normalized values of output $Q_{0}$, capital $K_{0}$ and labor $L_{0}$ according the theory of La Grandville (1989). The elasticity of substitution is denoted by $\sigma$ and the normalized distribution coefficients (input shares on output) by symbols $\pi_{0}=r_{0} K_{0} /\left(P_{0} Q_{0}\right)$ and $1-\pi_{0}$ where $r_{0} / P_{0}$ is the normalized value capital-price/output-price ratio. Capital and labor productivity is $A_{K t}$ and $A_{L t}$. In general, we do not consider the neutrality of total factor productivity, so it is augmenting both capital and labor.

Klump, McAdam, Willman (2012) highlight the importance of proper normalization of the production function. Normalized values should correspond to the actual measured values at the basic normalization point. In a transitive economy such as Slovakia, inputs and output of the production function are dynamically evolving and therefore it is difficult to estimate the basic normalization point.

Let us consider a representative firm whose production possibilities are described by the production function (1). The Firm maximizes its profit by choosing inputs $K_{t}$ and $L_{t}$. The first order conditions can be written by input demand relations in the form (Klump, McAdam, Willman, 2012): 


$$
\begin{gathered}
\log \left(\frac{r_{t}}{P_{t}}\right)=\log \left(\pi_{0} \frac{Q_{0}}{K_{0}}\right)+\frac{1}{\sigma} \log \left(\frac{K_{0}}{Q_{0}}\right)+\frac{1}{\sigma} \log \left(\frac{Q_{t}}{K_{t}}\right)+\frac{\sigma-1}{\sigma} \log A_{K t} \\
\log \left(\frac{w_{t}}{P_{t}}\right)=\log \left[\left(1-\pi_{0}\right) \frac{Q_{0}}{L_{0}}\right]+\frac{1}{\sigma} \log \left(\frac{L_{0}}{Q_{0}}\right)+\frac{1}{\sigma} \log \left(\frac{Q_{t}}{L_{t}}\right)+\frac{\sigma-1}{\sigma} \log A_{L t}
\end{gathered}
$$

where input-price/output-price ratios are denoted by $r_{t} / P_{t}$ and $w_{t} / P_{t}$.

The input demand relationships may be written in econometric specifications in the form (Chirinko, Mallick, 2017):

$$
\begin{gathered}
y_{K t}=\beta_{K 0}-\sigma x_{K t}+\beta_{K} t+v_{K t} \\
y_{L t}=\beta_{L 0}-\sigma x_{L t}+\beta_{L} t+v_{L t}
\end{gathered}
$$

where $y$ 's denote natural logarithm of input/output ratios:

$$
\log \left(\frac{K_{t}}{Q_{t}}\right)=y_{K t} \quad \text { and } \log \left(\frac{L_{t}}{Q_{t}}\right)=y_{L t}
$$

and $x$ 's denote natural logarithm of input-price/output-price ratios:

$$
\log \left(\frac{r_{t}}{P_{t}}\right)=x_{K t} \text { and } \log \left(\frac{w_{t}}{P_{t}}\right)=x_{L t}
$$

Assuming that capital- and labor-augmenting innovations are constantly growing, $\beta_{K}$ and $\beta_{L}$ coefficients depend on the corresponding technology growth rates and the start-up values:

$$
\begin{aligned}
& \beta_{K}=\gamma_{K} \frac{\sigma-1}{\sigma} \log \left(A_{K}\right) \\
& \beta_{L}=\gamma_{L} \frac{\sigma-1}{\sigma} \log \left(A_{L}\right)
\end{aligned}
$$

where $\gamma_{K}$ and $\gamma_{L}$ are growth rates, and $A_{K}, A_{L}$ are the start-up values of the innovations. Technological shocks are included in the random components $V_{K t}$ and $V_{L t}$, which we assume to meet the basic assumptions of the linear econometric model. We will discuss these assumptions more in the methodological section. The process of normalization (La Grandville, 1989) influences the parameters $\beta_{K 0}$ and $\beta_{L 0}$ but the estimation of the elasticity of substitution $\sigma$, so that we have eluded the theoretical problem. We assume that the first order conditions of a representative firm are met in the long run.

However, according to Chirinko, Mallick (2011), if relations (4) and (5) are cointegrated, $\sigma$ does not measure elasticity of substitution. The authors' doubt arises from the theoretical assumptions of input shares. Let us assume that relations (4) and (5) are cointegrated. The logarithms of labor and capital shares can be written in the form: 


$$
\begin{aligned}
& \rho_{K t}=\log \left(\frac{r_{t} K_{t}}{P_{t} Q_{t}}\right)=x_{K t}+y_{K t} \\
& \rho_{L t}=\log \left(\frac{w_{t} L_{t}}{P_{t} Q_{t}}\right)=x_{L t}+y_{L t}
\end{aligned}
$$

By substituting relations (4) and (5) into the input shares (8) and (9)) we obtain:

$$
\begin{gathered}
\rho_{K t}=(1-\sigma) x_{K t}+\beta_{K 0}+\beta_{K} t+v_{K t} \\
\rho_{L t}=(1-\sigma) x_{L t}+\beta_{L 0}+\beta_{L} t+v_{L t}
\end{gathered}
$$

According to neoclassical theory, the labor share (and its logarithm) is stationary. With respect to the relation (7), the labor share (11) is stationary only if $\sigma=1$. The $\sigma$ coefficient does not measure the elasticity of substitution.

Both capital/output ratio and capital-price/output-price ratio are stationary and the necessary condition for cointegration (4) is not fulfilled. If there is a cointegration relationship (4) or (5) with $\sigma \neq 1$, this relationship is driven by different underlying processes, and $\sigma$ cannot be interpreted as the elasticity of input substitution.

To estimate the elasticity of substitution, we need to use relations (4) and (5). If not cointegrated, they are affected by short-term shocks. Therefore, Chirinko and Mallick (2017) proposed to filter out the processes caused by short-term shocks (business cycle) from the input/output and input-price/output/price ratios using the Baxter, King (1999) frequency filter. We obtain the stationarized forms of (4) and (5) by their differentiating:

$$
\begin{gathered}
\Delta\left(y_{K t}\right)=\beta_{K}-\sigma \Delta\left(x_{K t}\right)+u_{K t} \\
\Delta\left(y_{L t}\right)=\beta_{L}-\sigma \Delta\left(x_{L t}\right)+u_{L t}
\end{gathered}
$$

To estimate the elasticity of substitution, we will estimate the specifications (12) and (13). We will modify the time series of logarithms of input/output ratios and their inputprice/output-price ratios by the frequency filter.

\section{Data}

Electronic macroeconomic database of the National Bank of Slovakia provides the quarterly capital stock data series estimate. Therefore we use this portal to gather all other quarterly data series ${ }^{1}$. The data series are in current prices and seasonally adjusted. All gathered data are seasonally adjusted except interest rates. To assure the correctness of our process, we normalized all used price deflators to the value 1 in the 2010:Q4 period and re-computed the data-series in constant prices. We use real seasonally adjusted GDP and its deflator to measure the output volume and its price.

\footnotetext{
${ }^{1}$ http://www.nbs.sk/en/monetary-policy/macroeconomic-database/macroeconomic-database-chart
} 
To find the volume of capital we firstly need to compute the net investment deflator. The net investment in current prices is measured as the first difference of the capital stock. Let us define a net capital creation as the difference between gross capital creation and the consumption of the capital. We computed the net capital creation in both current and constant prices and so we gathered the net capital formation deflator. The deflator we use to compute net investment in constant prices from the nominal net investment. As our deflators are normalized for the 2010:Q4 period, the capital stock in constant prices equals to the capital stock in current prices in this period. Subtracting the net investment from capital stock in constant prices, we gain the capital stock in constant prices before this period, and, reversely, cumulating the net investment to the capital stock in constant prices, we gain capital stock in constant prices after this period.

The capital price is the sum of interest and depreciation rates. We use the interest rate on loans to non-financial corporations and interest rate on deposits of non-financial corporations. According to the two interest rate use, the data set version doubles. We measure the depreciation rate as the consumption-of-the-fixed-capital/capital-stock ratio in constant prices.

The labor can be measured by three official data series of employment gathered by Statistical Office of the Slovak Republic. The first data series is gathered using Labor Force Review and it measures number of persons. The second and third are gathered using European system of national and regional accounts (ESA). The second measures the number of persons and the third the hours worked. Since we have three measures of the labor, the data set versions are three times more. The indication of the dataset versions is in the Table 1.

\section{Table 1: Dataset versions}

\begin{tabular}{lll}
\hline dataset version & capital price measurement & labor measurement \\
\hline (a) & loans to non-financial corporations & Labor Force Review \\
(b) & deposits of non-financial corporations & Labor Force Review \\
$($ c $)$ & loans to non-financial corporations & $E S A /$ persons \\
$($ d $)$ & deposits of non-financial corporations & $E S A$ / persons \\
$($ e $)$ & loans to non-financial corporations & $E S A /$ hours \\
$($ f & deposits of non-financial corporations & $E S A /$ hours \\
\hline
\end{tabular}

Source: Own consideration

To achieve the labor price, we gather the labor income data series. Dividing by the labor, we gain the labor price. To derive dataset we followed Gollin (2002) who refers an 
inconsistency between a theory and observed values of labor share. This inconsistency comes from incorrect calculation of labor share. Compensation to employees is not suitable indicator for labor income because they exclude proprietors (self-employed) labor income. It is unclear how the income of self-employed workers should be categorized in the labor-capital dichotomy. Gollin (2002) introduced several ways to modify data for correct labor share calculation. Our choice is limited by the published data. Some ways need indicators that are published but with small range, or they are annual, or we miss corresponding deflators. We use compensation per employee as a shadow price of labor of self-employed workers, i.e. labor income in extensive form is:

$$
\text { labour income }=\left(1+\frac{\text { self employed }}{\text { total employment }}\right) \cdot \text { compensation to employees }
$$

Baxter, King (1999) suggested appropriate frequency filter. The filter is sensitive to the selection of frequency length (lead/lags) for the moving average, and the low and high values for the cycle period. We use the frequency respond function to find that Baxter and King's suggested selection of 3 year frequency length ( $m=12$ quarters), 1.5 year (6 quarters) low and 8 year (32 quarters) high cycle period is proper. We made experiments filtering data with other combinations of the frequency length and cycle periodicity. Our dataset uses the period $1997-2014$ (2nd quarter). ${ }^{2}$ After filtering we lose the first $m$ and the last $m$ observations.

\section{Methodology}

By estimating the coefficients of (12) and (13), under assumption of a correlation between error terms $u_{K}$ and $u_{L}$, but we should consider these two equations as a system. Then the system (12) and (13) is called seemingly unrelated regression system and is referred to in the econometric literature as the SUR method (Hatrák, 2007, p. 345). The correlation of error terms $u_{K}$ and $u_{L}$ was tested by Breusch and Pagan test (Hatrák, 2007, pp. 356-357). Testing statistics with $\times 2$ asymptotic distribution and $m(m-1) / 2$ (i.e. 1 with $m=2$ equations) degrees of freedom is calculated as the product of the number of observations and the sum of the second powers of the correlation coefficients between residuals. Since $m=2$, we consider just 1 coefficient of correlation between the residuals. The values of the calculated test statistics $\lambda$ are given in the last row of Table 2 .

Since we state the correlation between error terms, we estimated the system (12) and (13) using the SUR method and different versions of our databases. Estimates are shown in Table 2. Serial correlation was tested by a general (portmanteau) autocorrelation test (Lütkepohl, 2005). To eliminate autocorrelation, we needed to modify the specifications by dummy variables corresponding to nonrecurring deviations during the financial crisis

\footnotetext{
2 The upper limit is given by an availability of the consumption of fixed capital in current prices data series.
} 
or during the entry of Slovakia into the European Monetary Union at the end of the first decade of the 21 st century.

The unit root of residuals was tested by the augmented Dickey and Fuller and Phillips Peron tests (see Lukáčik, Lukáčiková, 2008) stating that residuals are stationary. We preferred the later test, if many autoregressive terms solved autocorrelation in the test specification.

In the case of endogeneity of $\Delta x^{\prime}$ s in (12) and (13) we should estimate the simultaneous system using proper instrumental method. We tried to form instrument sets from the lagged data series related in the Table 1, aggregate demand data series, such as total aggregate demand, home aggregate demand, total final consumption, private final consumption, government final consumption, gross capital formation and their lags. Dataset were gathered from the same resource and processed by the same way as it is noted in the data section (filtered logarithmed and differentiated). However, applying the Hausman test of exogeneity using various instrument sets, we state that $\Delta x^{\prime}$ s in (12) and (13) are exogenous.

According to the results, the capital and labor demand on the supply side is affected by (seemingly unrelated) supply shocks. But demand shocks, by which theory assumes the endogenity of price ratios and the simultaneous relationship between the input/output ratios and input-price/output-price ratios, have not been confirmed. So modifying the time series from the business cycle frequency, we have probably managed to eliminate the demand shocks. Or, using frequency filters, we have eliminated both demand and supply business cycle shocks from the time series used. According to macroeconomic theory, supply shocks may affect not only short-term economic activity but also long-term trends. In such a case, the correlation of random components in both relationships could only be due to long-term supply shocks.

\section{Results}

The SUR estimates of the elasticity of substitution using the system (12) and (13) are in the Table $2,2^{\text {nd }}$ row. One asterisk signifies the statistical significance at a $5 \%$ significance level and two asterisks at a $1 \%$. Versions of used databases correspond to combinations according to different expressions of capital and labor and its prices (see Table 1). In the other rows there are standard deviations; each of the two equations of the system (12), (13) is assigned one determinant coefficient for the different versions of the database used. The values of the residual correlation test statistics with $\mathrm{X} 2$ asymptotic distribution and with 1 degree of freedom are in the last row of the table. The corresponding critical table value at the significance level of 0.01 is 6.644 ; therefore we have rejected the hypothesis of the non-correlation of residuals in all cases confirming the use of the SUR method in estimating the coefficients 
Table 2: SUR estimation of the elasticity of substitution.

\begin{tabular}{l||l|l|l|l|l|l} 
Version & $(\mathbf{a})$ & $(\boldsymbol{b})$ & $(\boldsymbol{c})$ & $(\boldsymbol{d})$ & $(\boldsymbol{e})$ & $(\boldsymbol{f})$ \\
\hline$\sigma$ & $0.041^{* *}$ & $0.048^{*}$ & $0.031^{*}$ & $0.048^{*}$ & $0.090^{* *}$ & $0.105^{* *}$ \\
\hline std. dev. & $(0.015)$ & $(0.021)$ & $(0.015)$ & $(0.022)$ & $(0.020)$ & $(0.025)$ \\
\hline$R^{2}(12)$ & 0.763 & 0.802 & 0.712 & 0.792 & 0.780 & 0.811 \\
\hline$R^{2}(13)$ & 0.746 & 0.747 & 0.670 & 0.672 & 0.535 & 0.540 \\
\hline$\lambda$ & 31.007 & 26.431 & 37.206 & 30.250 & 14.014 & 9.453
\end{tabular}

Source: Own consideration

We state that the elasticity of input substitution in the Slovak economy is very low but statistically significantly different from 0 . Its value ranges from 0.03 to 0.11 according to the choice of the database version.

\section{Conclusion}

Comparing our results with the novel estimates around the world, the Slovak elasticity of substitution is relatively low. Chirinko, Mallick (2017) used U.S. data modified by frequency filter. Their estimate of the elasticity of substitution is about 0.40 . The estimate of Klump, McAdam and Willman (2007) based on the U.S. data and three equation supply side simultaneous system is even higher. However, reviewing other empirical studies (Chirinko, 2008; Klump, McAdam, Willman, 2014), there are papers estimating an elasticity of substitution closed to 0 .

Slovak production possibilities correspond rather to the Leontiev production structure with little substitutability of inputs than to the Cobb-Douglas structure. Comparing with the U.S. economy, the lower value of substitution elasticity could partially explain the lower economic activity in Slovakia.

\section{Reference}

BAXTER, M., KING, R. G. (1999). Measuring Business Cycles: Approximate Band-Pass Filters for Economic Time Series. The Review of Economics and Statistics, 1999, Vol. 81, No. 4, s. 575-593.

CABALLERO, R. J. (1994). Small Sample Bias and Adjustment Costs. The Review of Economics and Statistics, 1994, Vol. 76, No. 1, s. 52-58.

CHIRINKO, R. S., (2008). б: The long and short of it. Journal of Macroeconomics, 2008, Vol. 30, No. 2, s. 671-686.

CHIRINKO, R. S., MALLICK, D. (2017). The Substitution Elasticity, Factor Shares, and the Low-Frequency Panel Model. American Economic Journal: Macroeconomics, 2017, Vol. 9, No. 4, s. 225-253.

CHIRINKO, R. S., MALLICK, D. (2011). Cointegration, factor shares, and production function parameters. Economic Letters, 2011, Vol. 112, No. 2, s. 205-206. 
GOLLIN, D. (2002). Getting Income Shares Right. Journal of Political Economy, 2002, Vol. 110, No. 2, s. $458-474$.

HATRÁK, M. (2007). Ekonometria. 1. vyd. Bratislava: IURA edition, 2007.

JONES, C. I., (2003). Growth, Capital Shares, and a New Perspective on Production Functions. Mimeo, University of California Berkeley and NBER. [Cit. 2018-06-07] Dostupné z http://www.frbsf.org/economic-research/files/jones_alpha100.pdf

KLUMP, R., MCADAM, P., WILLMAN, A. (2007). Factor Substitution and Factor Augmenting Technical Progress in the US. Review of Economics and Statistics, 2007, Vol. 89, No. 1, s. 183-192.

KLUMP, R., MCADAM, P., WILLMAN, A. (2012). The Normalized CES Production Function: Theory and Empirics. Journal of Economic Surveys, 2012, Vol. 26, No. 5, s. 769-799.

LA GRANDVILLE, O. DE (1989). In Quest of the Slutzky Diamond. American Economic Review, 1989, Vol. 79, No. 3, s. 468-481.

LA GRANDVILLE, O. DE (2009). Economic Growth. A Unified Approach. 1. vyd. New York: Cambridge University Press, 2009.

LUKÁČIK, M., LUKÁČIKOVÁ, A. (2008). Význam testovania stacionarity v ekonometrii. Ekonomika a informatika, 2008, Vol. 6, No. 1, s. 146-157.

LÜTKEPOHL, H. (2005). New Introduction to Multiple Time Series Analysis. 1. vyd. Berlin: Springer, 2005.

NÁRODNÁ BANKA SLOVENSKA (2018). Makroekonomická databáza. NBS. [Cit. 2018-06-07] Dostupné z http://www.nbs.sk 